\title{
THYMIC CYST- PRESENTED CLINICALLY AS A UNILATERAL CERVICAL SWELLING IN THE NECK IN A 7 YEAR FEMALE CHILD.
}

Mamina Bhoi ${ }^{1}$, P. Narmadha르, C. Subramanian³ ${ }^{3}$ Rehana Tippoo ${ }^{4}$, P. Viswanathan ${ }^{5}$.

1. III rd Year Post Graduate, Department of Pathology, Rajah Muthiah Medical College, Annamalai University

2. II nd Year Post Graduate, Department of Pathology, Rajah Muthiah Medical College, Annamalai University

3. H.O.D. Department of Surgery, Rajah Muthiah Medical College, Annamalai University

4. Professor, Department of Pathology, Rajah Muthiah Medical College, Annamalai University

5. Professor, Department of Pathology, Rajah Muthiah Medical College, Annamalai University

\section{CORRESPONDING AUTHOR:}

Dr. P. Viswanathan,

Rajah Muthiah Medical College,

Annamalai University, Chidambaram,

Tamilnadu, India. Pin-608002.

E-mail: drpviswanathan2013@gmail.com

\section{HOW TO CITE THIS ARTICLE:}

Mamina Bhoi, P. Narmadha, C. Subramanian, Rehana Tippoo, P. Viswanathan. "Thymic Cyst- Presented Clinically as a Unilateral Cervical Swelling in the Neck in a 7 year Female Child". Journal of Evolution of Medical and Dental Sciences 2013; Vol2, Issue 26, July 1; Page: 4729-4732.

ABSTRACT: INTRODUCTION: Isolated Thymic cysts are very uncommon lesions and are believed to account for approximately $3 \%$ of all anterior mediastinal masses (1). Thymus is derived from $3^{\text {rd }}$ pharyngeal pouches with only a small contribution from $4^{\text {th }}$ pharyngeal pouches. CASE REPORT: An upper lateral neck swelling on the left side of short duration which was diagnosed pre-operatively as, branchial cyst, in a 7 year female child. There were no symptoms of pain or obstruction. Excision biopsy was done and the histopathological diagnosis was confirmed as Thymic cyst. Embryological and histological aspect with review of literature has been done.

KEY WORDS: Cervical swelling, Unilateral, Thymic Cyst.

INTRODUCTION: Thymic Cysts are rare and are believed to account for approximately $3 \%$ of all anterior mediastinal masses.

Thymus is derived from $3^{\text {rd }}$ pharyngeal pouches with only a small contribution from $4^{\text {th }}$ pharyngeal pouches. By $8^{\text {th }}$ week of development there is incomplete fusion of lower poles and they are carried into antero superior mediastinum by its attachment to pericardium. Sometimes, thereafter hematopoietic stem cells colonize these structure and Hassall's corpuscles appears. Corticomedullary differentiation occurs somewhat later. If it fails to descend, thymus remains in ectopic position in neck.

HISTOLOGY: Thymus is encapsulated with fibrous septa extending into the organ to give it branched or lobulated appearance. Epithelial cells of thymus form a reticular framework and lymphocytes are situated in intercellular spaces between epithelial cells. Darker appearing cortex and lighter appearing medulla are due to dense package of lymphocytes in cortex and Hassall's 
corpuscles (whorls of medullary epithelial cells with their characteristic keratinized cores) in medulla respectively. Macrophages, mast cells, plasma cells, eosinophils, fibroblasts and scattered myoid cells (muscle like cells) are seen. At birth it weighs 10 to 35gm.Grows until puberty, when it achieves a maximum weight of 20 to $50 \mathrm{gm}$. Then physiologic involution occurs with fatty infiltration of organ and loss of lymphocytes. Few epithelial cells become spindly and Hassall's corpuscles often form cyst or calcify. In the elderly it weighs 5 to $15 \mathrm{gm}$.

CASE REPORT: 7 year old female child presented to the surgical OPD with complains of swelling over left side of the neck for short duration. The swelling was insidious in onset and progressive in nature, gradually increased to the present size. There were no symptoms of pain or obstruction. There was no history of change of voice or difficulty in breathing or swallowing. Family history was nil relevant.

ON EXAMINATION:

- The swelling was $3.5 \times 3.5 \mathrm{~cm}$, present on the left side of the neck, between the angle of the mandible and upper inner border of left sternocleidomastoid muscle.

- The swelling was soft and cystic, fluctuant, transillumination positive. No dilated veins. Opposite side of the neck was normal. Trachea was normal in position.

FNAC: Showed cholesterol crystals with signs of a degenerated cyst.

CAROTID DOPPLER: Left Common Carotid Artery was pushed posteriorly due to a $3.5 \mathrm{x} 3 \mathrm{~cm}$ cystic mass.

OPERATIVE PROCEDURE: Excision biopsy was done under GA. Intra operative findings - Cystic mass was identified adherent to carotid sheath and blunt dissection was made. The cyst was sent for histopathological examination.

MACROSCOPY: Gross examination of the specimen revealed a single, grey white, grey brown, cystic mass measuring $3.5 \times 3.5 \mathrm{~cm}$ in diameter (Figure 1). Cross section revealed multiple cysts, largest cyst measuring $1.5 \mathrm{~cm}$ in diameter and smallest cyst measuring $0.5 \mathrm{~cm}$ in diameter, and were filled with gray brown material (Figure 2).

LIGHT MICROSCOPIC FINDINGS - H \& E SECTIONS: Multiple sections studied from the cyst reveal a multiloculated cyst lined by flattened cells (Figure 3). Some areas show low cuboidal and other areas exhibit fine cilia. Cyst wall shows cholesterol granulomas with proteinaceous fluid (Figure 4), along with aggregates of thymocyte and Hassall's corpuscles (thymic tissue) (Figure 5\&6). Cyst wall also shows fibrotic changes.

With the above histological features,the diagnosis of Thymic cyst was confirmed.

DISCUSSION: Thymic Cysts can be divided into two distinct types:

1) Unilocular Thymic Cyst (developmental origin) results from failure of obliteration of thymo-pharyngeal duct during development (1). Generally small and located in the neck more often than mediastinum. The cervical cysts tend to be elongated and can be found 
anywhere along a line extending from the angle of mandible (lateral neck) to the manubrium sternum. Lesions are often asymptomatic and found incidentally on radiological examination. Chest X-ray studies show a smooth and sharply defined contour.

2) Multilocular Thymic cyst (likely an acquired process of a reactive nature): It is multilocular (2,), filled with turbid, cheesy or haemorrhagic material and always accompanied by inflammation and fibrosis. It can be an incidental finding or result in a large tumor like mass adherent to other mediastinal structures. Lining may be flat, cuboidal, ciliated columnar or often squamous. Occasionally features of pseudoepitheliomatous hyperplasia (4). Cholesterol granulomas are common. In some cases the inflammatory infiltrate is very prominent, with formation of numerous lymphoid follicles. The majorities of cases are generally asymptomatic and discovered on routine chest X-ray studies (5). Some patients however may present with symptoms of dyspnea or chest discomfort. On computed tomography scan, the lesions are usually multilocular and sharply demarcated from mediastinal fat and soft tissue.

The following are the differential diagnosis for mediastinal masses versus thymic cyst in the mediastinum:

1. Hodgkin's Lymphoma-Nodular sclerosis

2. Seminoma

3. Thymoma

4. Mature Teratoma.

TREATMENT: Simple excision is the treatment of choice with follow up of patient.

CONCLUSION: Thymic cysts are rare lesions. They make up to $3 \%$ of all mediastinal masses. Inflammation in Thymic Cysts is idiopathic, although in some cases a specific etiology (HIV infection, Autoimmune Disorder) is to be ruled out.

ACKNOWLEDGEMENT: We take the privilege of thanking the Medical Superintendent and the Dean, Faculty of Medicine, Prof. Dr. L. Lakshmana Rao, H.O.D. Department of Pathology, and the patient for allowing us to take on this case for presentation.

\section{REFERENCES:}

1. Rosai and Ackerman's, Surgical Pathology, Tenth Edition, Volume 1, 2011, 442-443.

2. Sternberg's Diagnostic Surgical Pathology, Fifth Edition, Volume 1, 2010, 1122-1124.

3. Weidner Cote Suster Weiss, Modern Surgical Pathology, Volume 1, 2003, 493-494.

4. Mishalani SH, Lones MA, Said JW. Multilocular thymic cyst. A novel thymic lesion associated with human immunodeficiency virus infection. Arch Pathol Lab Med 1995, 119: 467-470.

5. Suster S, Rosai J. Multilocular thymic cyst. An acquired reactive process. Study of 18 cases. Am J Pathol 1991, 15: 388- 398.

6. Suster S, Barbuto D, Carlson G, Rosai J. Multilocular Thymic Cysts with pseudoepitheliomatous hyperplasia. Hum Pathol 1991, 22: 455-460.

7. Ratnesar P. Unilateral cervical thymic cyst. J LaryngolOtol 1971, 85:293-298.

8. Dyer NH. Cystic thymoma and thymic cysts. A review. Thorax 1967, 22: 408-421.

9. Bleger RC, Mc Adams AJ. Thymic cysts. Arch Pathol 1966, 82: 535-541. 


\section{CASE REPORT}

\section{MACROSCOPY:}
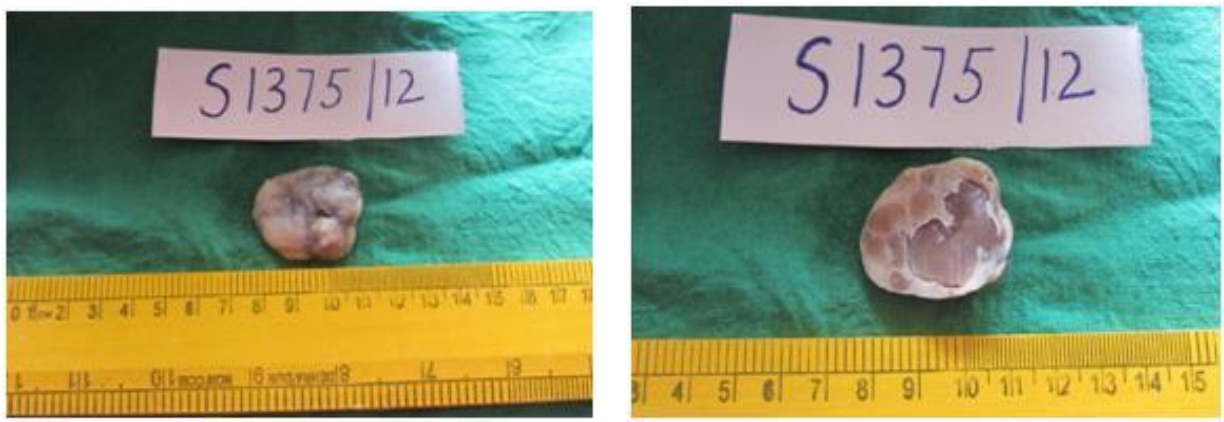

Fig 1: The entire cyst was grey brown $t$ o grey white, surface was bosselated, and was measuring $3.5 \times 3.5 \mathrm{~cm}$

\section{MICROSCOPIC PICTURES: H\&E SECTIONS:}

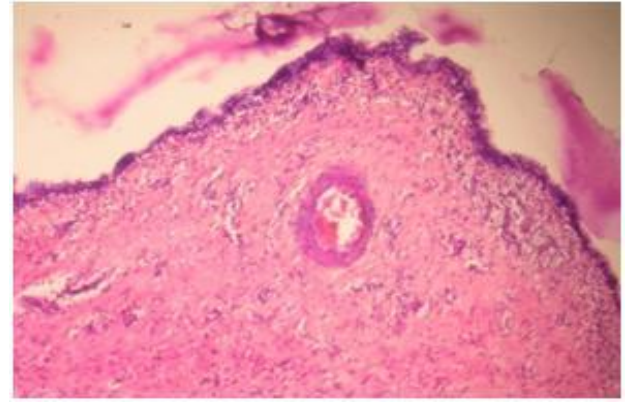

Fig 3: H\&E stained. 10X

Fig 3: The cyst wall is lined by flattened to low cuboidal cells.

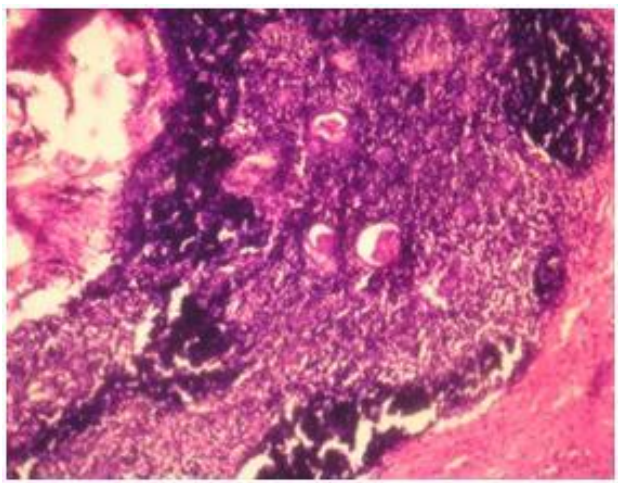

Fig 5: H\& E 20X
Fig 2: The cross section of the specimen revealed multiloculated cysts of varying sizes filled with grey brown material.

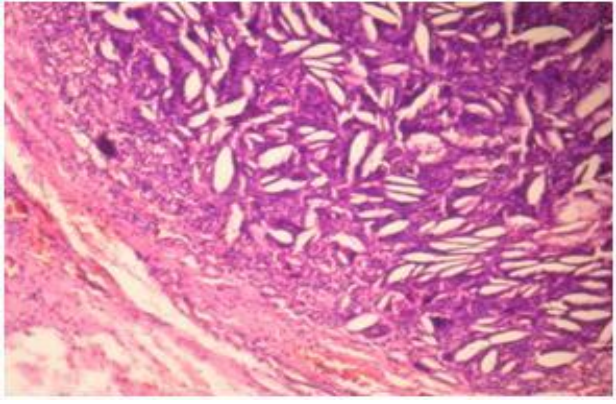

Fig 4: H\&E stained. 20X

Fig 4: The picture shows cholesterol granulomas.

Fig 5: The microscopic picture shows aggregate of lymphocytes and Hassall's corpuscles. The cyst is lined by flattened to low columnar epithelium.

- All the microscopic pictures were taken using Nikon Cool pix Model 8400.

- X-Indicates the power of Objective.

- Stain used - Haematoxylin and Eosin. 